\title{
Lessons Learned from the Construction of Kelly Lake TDA Embankment
}

\author{
Hany El Naggar ${ }^{1}$, Adam Marlin², Darren Dennis ${ }^{2}$ \\ ${ }^{1}$ Dalhousie University \\ 1360 Barrington St., Halifax, Canada \\ Hany.elnaggar@dal.ca \\ ${ }^{2}$ Nova Scotia Department of Transportation \& Infrastructure Renewal \\ 107 Perrin Dr., Fall River, Canada \\ Darren.Dennis@novascotia.ca; Adam.marlin@novascotia.ca
}

\begin{abstract}
The use of tire-derived aggregate (TDA) started gaining popularity in several highway infrastructure projects in Canada and around the world. Recycling scrap tires have several economic and environmental benefits, as TDA is often the most cost-effective material that can offer the engineering properties sought, in addition, its use eliminates the need to store waste tires in landfills saving precious landfill space. Nova Scotia Department of Transportation and Infrastructure Renewal (NSTIR) constructed a 450m full-scale test embankment off the northbound lanes of Highway 102 at Kelly Lake, Halifax, Nova Scotia, utilizing TDA processed from approximately 100,000 scrap tires to investigate the soil-structure interaction behaviour of an engineered TDA fill layer underneath rigid pavement. The purpose of this project is to demonstrate the engineering benefits of using TDA as a recycled non-traditional construction material. Utilizing the lessons learned from this demonstration project, NSTIR will pursue future applications of TDA in Nova Scotia for highway construction.
\end{abstract}

Keywords: Tire-derived aggregate (TDA), Recycling scrape tires, Highway construction, Soil-structure interaction, Rigid pavement

\section{Introduction}

Tire-derived aggregate (TDA) is an engineered construction material produced from recycled scrap tires. In the literature, TDA is often referred to as tire chips or tire shreds. It is an excellent lightweight fill alternative to using conventional earth fills in the construction of highway embankments on soft soils. TDA has excellent geotechnical properties, maintains its structural integrity, and weighs 50-60\% less than conventional earth fill [1]. TDA has been successfully used as embankment fill in several jurisdictions in North America since the early 1990s. The economic and environmental benefits of using TDA as a fill material are twofold: first, large volumes of used tires are diverted from landfill and stockpiles and, second, comparable volumes of non-renewable aggregates are saved. The lightweight characteristics of TDA make it a desirable construction material for embankments built on soft soils as it improves stability and reduces settlements. Furthermore, TDA has a lower coefficient of lateral earth pressure (50\% of conventional soil backfill) resulting in lesser lateral pressures on retaining walls. TDA can be used as good a thermal insulator as it has a thermal resistance that is about 7-8 times higher than conventional soil backfill; it also has great draining characteristics with high hydraulic conductivity generally greater than $1 \mathrm{~cm}$ per second. TDA is a compressible (low stiffness) material that can also be used to dampen the seismic effect and absorb vibrations. ASTM D6270-08, "Standard Practice for the use of Scrap Tires in Civil Engineering Applications" (ASTM, 2008) provides typical material properties for TDA. The American Society for Testing and Materials (ASTM) presents available TDA testing procedures, material characterization, design considerations, and construction practices for the use of processed tires as a substitute for conventional fill materials. This standard restricts the individual TDA layer thickness for embankment fills to $3 \mathrm{~m}$ and specifies the gradation and quality of the TDA to be used.

ASTM (2008) specifies two classes of TDA fills; Class I fills with TDA layers $<1 \mathrm{~m}$ thick and Class II fills with TDA layers ranging from 1-3 $\mathrm{m}$ thick. Also, material specifications for two size ranges of TDA are specified in the standard. Type $\mathrm{A}$ is proper for drainage, vibration damping, and insulation applications. Type B is suitable for use as an embankment fill material, retaining wall backfilling, and landfill drainage applications. TDA is not classified as a hazardous waste by the ASTM. Based on several studies conducted to support ASTM (2008), TDA has a negligible offsite effect on water quality. 
TDA was used for the first time in Canada in 2000 for the construction of a $300 \mathrm{~m}$ long embankment over soft ground to provide access to a gravel pit northeast of Winnipeg, Manitoba [2]. In 2007, TDA was used as lightweight fill to reconstruct a $130 \mathrm{~m}$ long section of highway embankment after the original embankment failed using conventional earth fill. The embankment failure occurred during construction of the Route 1 highway near St. Stephen, New Brunswick [3]. The embankment was approximately $12 \mathrm{~m}$ high when it failed, due to the underlying soft marine clay. The redesigned embankment included two layers of Type B TDA, each $3 \mathrm{~m}$ thick and fully wrapped in a woven geotextile. In 2012 a large-scale $80 \mathrm{~m}$ long test embankment was constructed in Edmonton, Alberta, to evaluate the performance of TDA in cold climate [4].

Even though several TDA embankments were built over the last two decades, yet, limited information exists on the design procedures and methodologies followed for each. The lack of comprehensive design guidelines is hindering the growth of the TDA use in Canada in general and in the province of Nova Scotia in particular. Thus, the primary goal of this research project is to understand the soil-structure interaction behaviour of TDA better and to optimize its design for the reconstruction of the Highway 102 Kelly Lake scale ramp reconstruction project to demonstrate the engineering benefits of TDA. Utilizing the lessons learned from this demonstration project, NSTIR will pursue future applications of TDA in Nova Scotia for highway construction.

\section{Background}

The Kelly Lake Scale site is located approximately $4 \mathrm{~km}$ northeast of Fall River, Nova Scotia (NS), Canada adjacent to the northbound lanes of NS Highway 102 (Fig. 1). The scale facility featured a deteriorated flexible pavement structure on the one lane exit and entrance ramps. The primary distresses included severe rutting and cracking. The approach to the scale house featured a two-lane rigid pavement over an approximate $30 \mathrm{~m}$ length that featured some minor faulting, cracking and spalling. The paved parking areas and bypass lanes were not included as part of the site works.

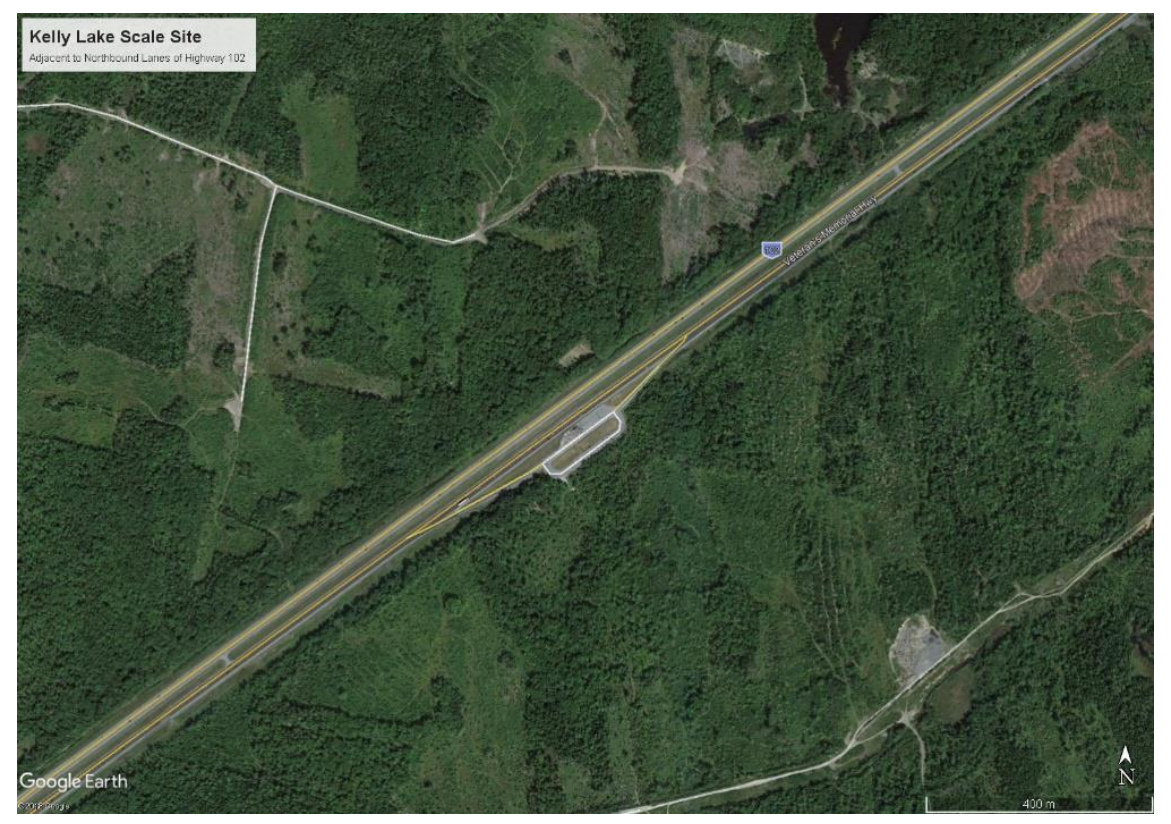

Fig. 1: Map image of Kelly Lake Scale Facility.

The deteriorated condition of the facility was causing complaints from the local trucking associations and staff. The Nova Scotia Department of Transportation and Infrastructure Renewal (Department) desired to upgrade the facility, 
mitigate existing causes of the pavement distress, and provide an opportunity to research and develop new technologies or materials that could aid in providing a long-lasting well-designed facility.

\section{Geotechnical Investigation}

In order to achieve these goals, a geotechnical investigation was undertaken to investigate the sub-surface conditions of of the facility. This was carried out by Exp Services Inc. under the supervision and direction of Highway Construction Services (HCS) staff. Fieldwork involved a preliminary site visit to locate borehole locations, and an additional site visit to to supervise the drilling of seven (7) boreholes along the approach, scale, and exit locations. The boreholes were advanced using coring and casing equipment to obtain samples of the asphalt and concrete pavement surfaces. Soil samples were obtained using a $50 \mathrm{~mm}$ split diameter split spoon sampler during the standard penetration tests (SPT) completed ahead of the auger drilling. Soil materials were classified in the field then taken to the laboratory for classification via the Unified Soil Classification System (USCS). Boreholes were advanced to depths ranging from $2.6 \mathrm{~m}$ to $8.5 \mathrm{~m}$. Asphalt and concrete depths were found to vary throughout the alignment. The granular materials directly beneath the asphalt or concrete were very poor with very high fines content. The fill was found to vary from slate fill to reworked glacial till to native glacial till. The geotechnical report [5] classified the reworked glacial till as clayey sand with gravel (SC) and the native till as clayey sand with gravel (SC) as well. This material was encountered at depths between $0.4 \mathrm{~m}$ and $0.7 \mathrm{~m}$ below the bottom of the asphalt or concrete surface.

The primary recommendations detailed in the geotechnical report included observations that the materials used for granular fill were poorly graded and compacted and did not meet current Department standards. The fine-grained subgrade soils had high fines contents, moist, poorly drained, were susceptible to pumping and transmitting fines into the overlying granular material, and highly susceptible to frost impacts. The area, in general, was noted to be inadequate in providing an opportunity for the pavement subbase and subgrade to drain. Removal and replacement of the fine-grained material and provision of sub-surface drainage improvements were recommended.

\section{Pavement Design}

Non-destructive testing was performed with the Department's Falling Weight Deflectometer (FWD) at regular intervals along the project segment. This testing was completed in concert with the geotechnical investigation. The resulting material layer thicknesses and classifications were used, in conjunction with local climate data, to back-calculate the layer moduli via ELMOD6 software. The Department's Traffic Services and Vehicle Compliance divisions provided traffic information for the truck scale facility over a typical week and determined the Average Annual Daily Traffic (AADT) and truck percentage. HCS staff determined that, based on traffic, the nature of rapid deceleration and acceleration to and from highway speeds, standing truck traffic while queuing at the scale facility, and the existing subgrade materials, a jointed reinforced concrete pavement was the preferable pavement type to proceed to detailed design. HCS staff completed an initial design via ELMOD6 and confirmed with AASHTO 93 methodology. This pavement design was sent to be peer-reviewed by WS Langley Concrete \& Materials Technology Inc. The design parameters and final design are detailed in figure 2 and 3. 


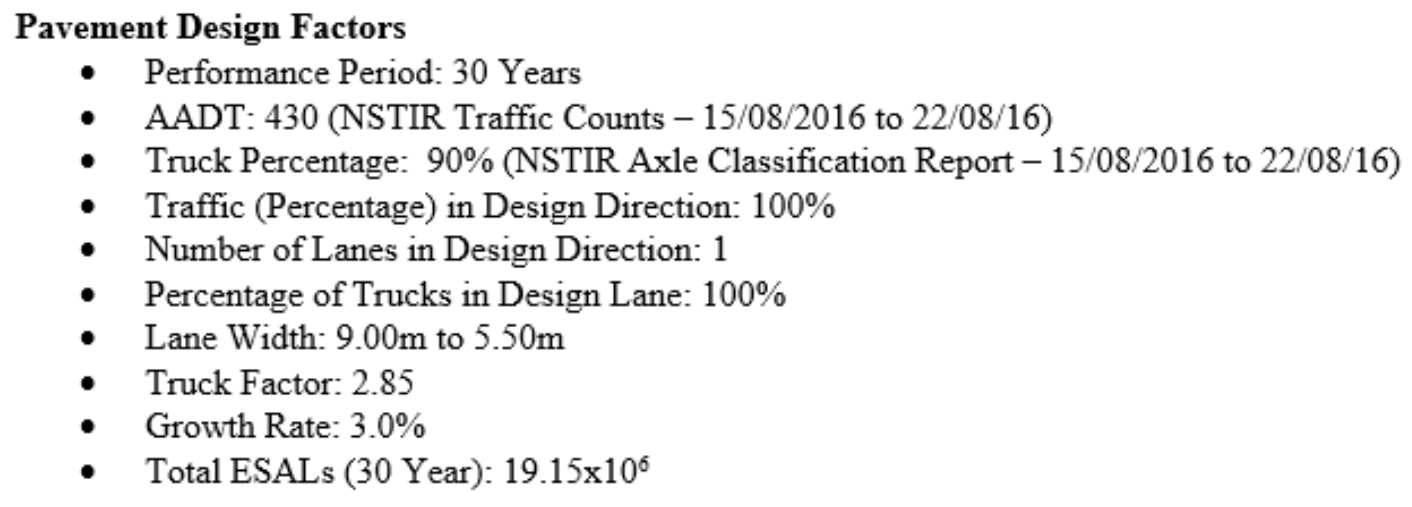

Fig. 2: Pavement Design Factors.

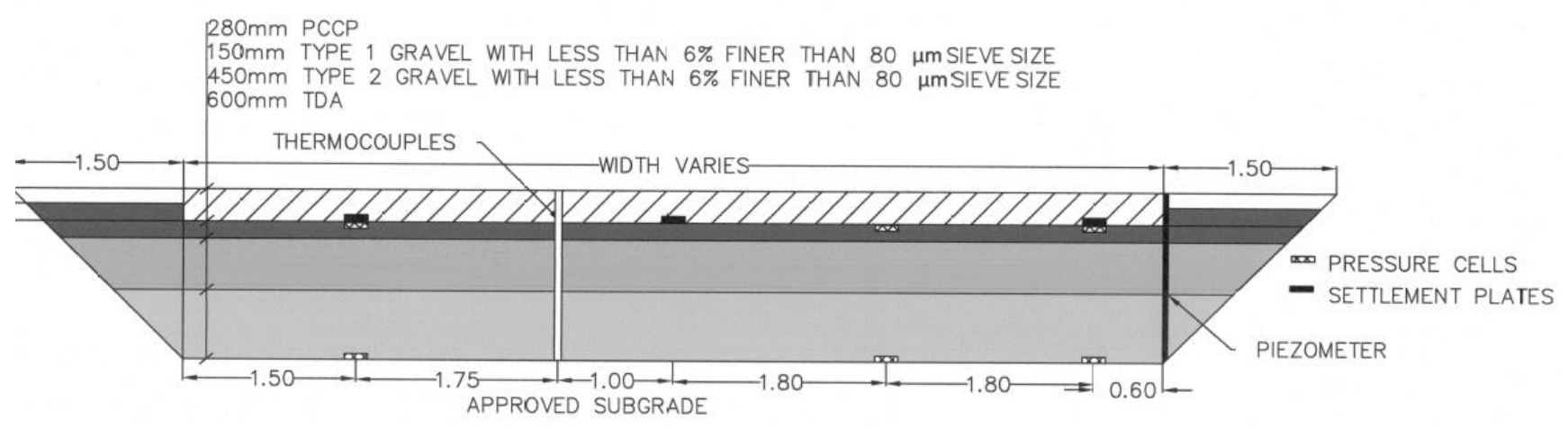

Fig. 3: Pavement Cross Section.

The Department recognized the opportunity to utilize this controlled off highway facility to research pavement materials, mitigate concerns related to the subgrade material, improve drainage, and partner with local industry and academia. The decision was made to include a layer of Tire Derived Aggregate (TDA) at a depth of $600 \mathrm{~mm}$. Dalhousie University and the supplier of the TDA, Halifax C\&D, partnered with the Department to provide specialized consulting services specific to TDA, monitor and inspect the TDA construction, and perform further design review via finite element modelling (FEM) of the current design. Dalhousie University would monitor data from the facility as an ongoing concern, use the available data to refine the design parameters of the TDA and create guidelines for the design and construction of TDA embankments for the Department. The decision was made to construct the $600 \mathrm{~mm}$ TDA layer out of ASTM Class 1 fill using TDA Type A as detailed in ASTM D6270[6]. The design included a small subsection that where the pavement cross section was constructed entirely out of granular material which was also metered for monitoring as a control cross section.

\section{Construction}

The successful contractor undertook the work at the beginning of May 2018. The initial work involved excavation of the paved surface materials, followed by removal of the unsuitable subbase and subgrade materials. Once excavation was completed to design subgrade elevations and suitable compacted the Department inspected and approved for TDA 
placement. At this time Department staff, Dalhouse research team and Halifax C\&D staff determined the final locations of several drains installed transversely and longitudinally to allow for the complete draining of the TDA layer along the entire alignment. Drains typically involved perforated pipe installed along a slope away from the pavement structure infilled with $150 \mathrm{~mm}$ minus clear stone to $50 \mathrm{~mm}$ minus clear stone. The lengths, depths, and directions of these drains were tailored to the location to best facilitate the drainage.

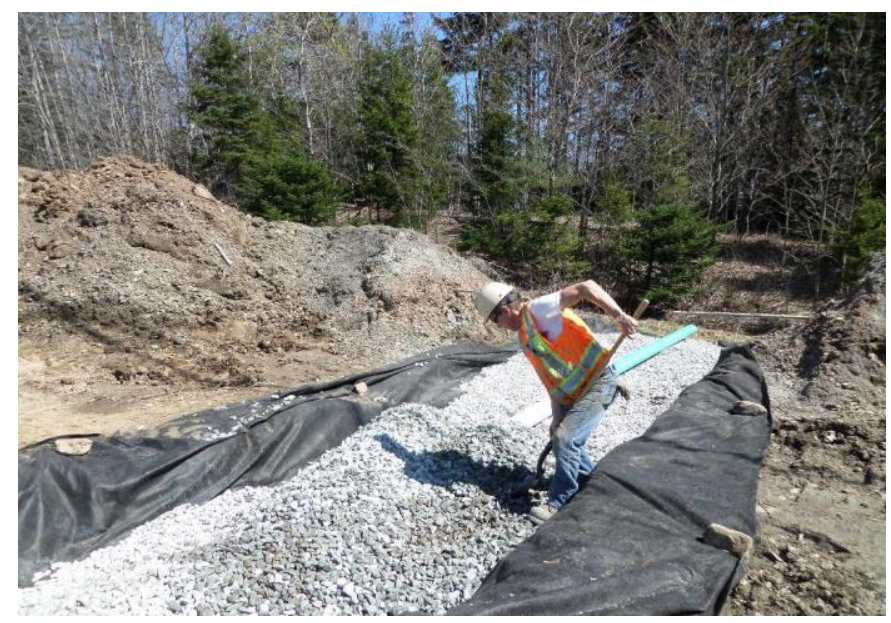

Fig. 4: Clear stone and perforated pipe drain installation.

The TDA material was placed on top of a heavyweight geotextile (Terrafix 600R), which was wrapped around the TDA in all dimensions. The TDA was placed, graded with a dozer to a mean $300 \mathrm{~mm}$ lift thickness, and compacted with a roller to the satisfaction of ASTM D6270. The contractor paid careful attention to the compactive effort and in all cases, the minimum effort was exceeded. Halifax C\&D as well as Department staff inspected and approved the placement of TDA prior to allowing granular subbase material to be placed.

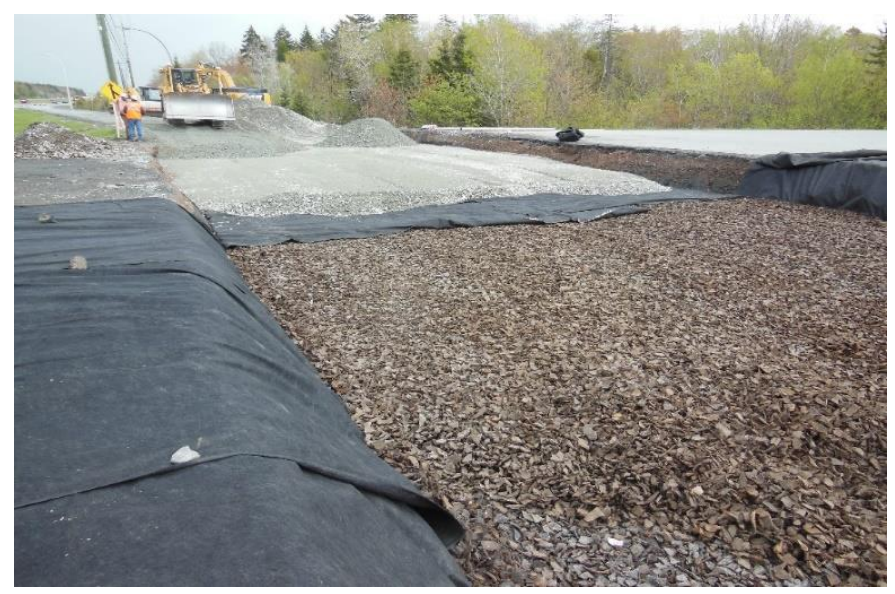

Fig. 5: Compacted TDA with type 2 subbase material placement occurring.

The granular subbase material was placed over the wrapped TDA and compacted following Department specifications. The contractor initially expressed concern about achieving compaction on the granular material placed directly on the TDA material however after establishing a rolling pattern, testing with a nuclear densometer, and proof rolling the material was 
surprised to find that the usual effort met or exceeded the specified levels of compaction required and was able to minimize effort during this part of the process, affording some time savings[7].

The TDA requirements that were specified included a two-week surcharge with material placed above the TDA to elevation of $150 \mathrm{~mm}$ above finished grade. The time and pressure provided during this surcharge allowed the secondary compression to occur within the $600 \mathrm{~mm}$ TDA layer in a controlled manner. This mitigated ongoing secondary (creep) that would be expected to occur over the life of the pavement structure. The contractor phased their work to for the reuse of the extra surcharge material from one prepared section of TDA and subbase material to another. Once completed the contractor had secured an offsite location where the excess surcharge material, in this case additional type 2 granular, could be used on another project.

Construction activities continued with this phased approach until all areas were prepared, type 1 base granular material was installed, graded and compacted, and each subsection was prepared for the Portland Cement Concrete Pavement (PCCP). The PCCP was installed in a phased approach like the TDA and surcharge material. The PCCP was designed as a jointed reinforced concrete pavement. The thickness was $280 \mathrm{~mm}$ of PCCP required to have a minimum 4.85 MPa flexural strength and $35 \mathrm{MPa}$ compressive strength. The mixture had a maximum aggregate size of $40 \mathrm{~mm}$ from a source required to be non-Alkali Aggregate Reactive as detailed in the Department's specifications. The pavement width varied from $8.45 \mathrm{~m}$ to $10.00 \mathrm{~m}$ along the approach ramp and from $10.02 \mathrm{~m}$ to $6.67 \mathrm{~m}$ along the exit ramp with the scale and associated underground appurtenances located approximately at the midpoint of the pavement (figure 6).
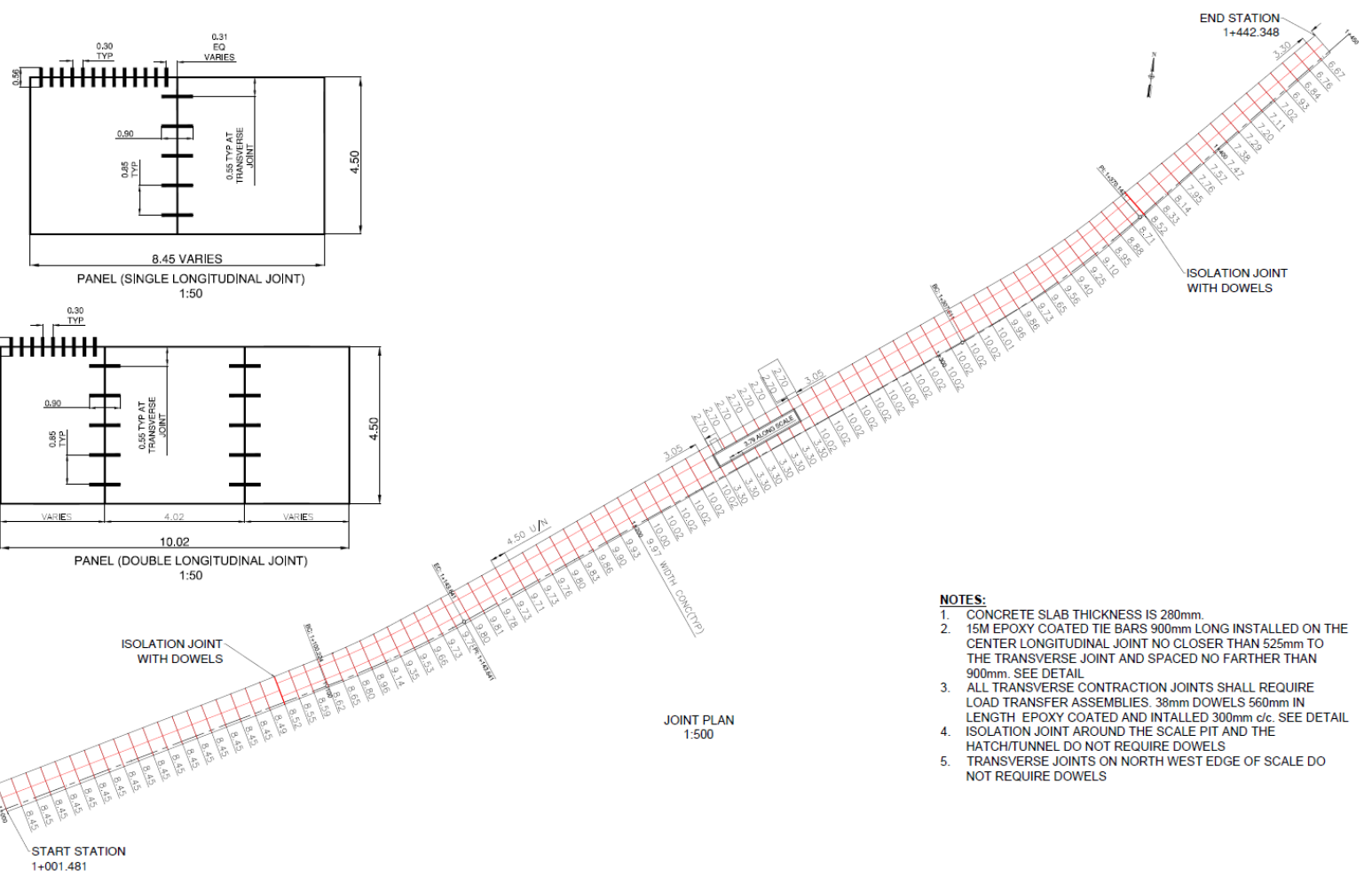

Fig. 6: PCCP joint plan and pavement.

The placement of the PCCP was phased like the previous phases of construction. The placement occurred in the summer months. This resulted in the placement occurring very early (well before dawn) and ending mid-morning. The initial placement was attempted by pumping the concrete mixture in front of the paver to avoid having to replace any dowel baskets after trucking. The concrete mixture on the first day's pour did not include ice in the batch. The 
combination of these two decisions resulted in very limited production on the first day due to high mix temperatures and placement issues. The following days' pours were all completed by delivering the concrete mixture via trucks and included included ice in the mixture. The first section placed was located at the southerly extents of the approach ramp (figure 7). The The contractor then completed PCCP placement of the northerly extents of the exit ramp.

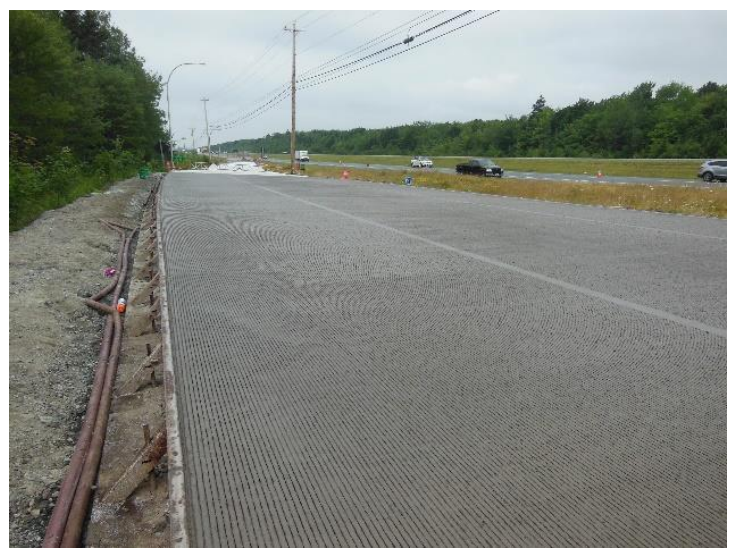

Fig. 7: PCCP view south to approach ramp showing tined surface.

Production continued in this staged manner culminating in the final concrete placement around the scale. The concrete placement adjacent to the scale proved to be challenging due to the scale and its appurtenances creating barriers to a continuous pour. The concrete was finished with a longitudinally tined surface and jointed every $4.5 \mathrm{~m}$. Dowel bar details were as per Department specifications and detailed in figure 6.

In partnership with Dalhousie University the Department installed pressure cells, settlement plates, piezometers and thermocouples at two locations along the project segment. One installation allows for the monitoring of the control section that was constructed with conventional granular fill. The other installation allows for the monitoring of the test section that represents most of the project segment and was constructed with a $600 \mathrm{~mm}$ layer of TDA. The facility allows for the accurate measurements of trucks passing through the site, and in addition to the monitoring within the pavement section, will allow for Dalhousie University staff to confirm actual secondary settlement, thermal properties, and structural characteristics of each material within the cross-section and refine design parameters used for these materials, specifically focusing on the TDA material.

\section{Lessons Learned}

The Department evaluated the project continuously throughout pre-construction, construction, and finalization of the contracted works. This allowed for evaluation of each segment with a focus on determining which aspects went well and where improvements could be made in the future. Firstly, for a project of this nature, featuring a scale and associated appurtenances, as well as a PCCP and the use of TDA, the Department required two mandatory meetings of potential bidders prior to the closing of the tender. This allowed for each proponent to ask questions and, if necessary, allowed the Department to address any items via addendums to assist in accurate and competitive bidding. This would be required for any future projects of this nature. Secondly, the estimation of the TDA material's cost to supply, place (including heavyweight geotextile), compact, and surcharge resulted in lower costs than the similar supply and placement of conventional granular fill. This was confirmed, based on calculations completed using the project's unit bid prices. The TDA cost approximately $50 \%$ less than the placement of the same depth of granular material. This, in addition to the environmental benefit of recycling waste vehicle tires, and the potential engineering benefits of drainage and insulation, yielded considerable benefit. Thirdly the installation of the TDA in a trenched scenario allowed sloping the materials and locating drainage trenches and pipes to facilitate a very well drained pavement cross section. This will improve the overall performance of the pavement, and the Department would require this on any future project where possible. 
The Department reviewed the installation of TDA and the heavyweight geotextile wrap. In the future, the would consider using a medium weight geotextile, which for this type of TDA is believed to offer similar separation performance and further reduce the costs of the TDA installation without jeopardizing any performance. The Department would also evaluate the 14-day surcharge requirement for TDA, consider requiring onsite material be used for surcharge, increasing the time and decreasing material so that the specified construction materials could be used for surcharge. The time and material used for surcharge both increased costs to the Department. It is acknowledged that the secondary settlement of the TDA must be allowed to occur to improve the performance of the PCCP and pavement structure however this should be refined and optimized based on values measured from this TDA project and for the site specifics on any future project segment.

The PCCP was placed in a staged manner which resulted in several construction joints which may have been avoided if the requirement to pave in a continuous manner in one direction would have been required. This will be evaluated on future projects. The Department also designed the PCCP to match the pre-existing widths of the asphalt pavement with only slight changes. This resulted in some placement challenges, longitudinal joint location changes, additional isolation joints, and equipment adjustments. For future projects, the Department will strive to design the PCCP to a uniform width that suits the project requirements and minimize the length of any tapers. Tapers will be constructed with flexible pavement if that material suits the location's usage. The Department also tendered this PCCP with the requirement that the contractor completes the jointing plan subject to the Department's approval. This was due to the unknown dimensions of the scale and scale pit installation which was tendered as a 'design-build' item. On future projects, the Department will complete the jointing plan to facilitate an accurate and fair bid while ensuring a well-performing PCCP.

\section{Conclusion}

This successful demonstration project confirmed the beneficial use of TDA as a recycled engineered material to construct highway embankments at selected locations in Nova Scotia. The gained experience and lessons learned in this demonstration project will be used to support future use of TDA at other sites in Nova Scotia for highway construction, including embankment fill and backfill for retaining walls and bridge abutments. In this project, the TDA cost was approximately $50 \%$ less than using conventional granular material. This is in addition to the environmental benefit of recycling waste vehicle tires, and the potential engineering benefits of drainage and insulation which yield considerable additional benefits.

\section{References}

[1] H. El Naggar, P. Soleimani, and A. Fakhroo, "Strength and Stiffness Properties of Green Lightweight Fill Mixtures," Geotechnical and Geological Engineering, vol. 34, no. 3, pp. 867-876, 2016.

[2] A. Shalaby, and R. A. Khan, "Design of unsurfaced roads constructed with large-size shredded rubber tires: a case study," Resources, Conservation and Recycling, vol. 44, no. 4, pp. 318-332, 2005.

[3] B. Mills, H. El Naggar, and A. J. Valsangkar. "North American overview and Canadian perspective on the use of tire derived aggregate in highway embankment construction," in Ground improvement case histories, Indraratna and Chu, Ed. New York: Elsevier, 2015, chap. 22, vol. 2.

[4] D. Meles, A. Bayat, and D. Chan, "One-dimensional compression model for tire-derived aggregate using large-scale testing apparatus," International Journal of Geotechnical Engineering, vol. 8, no. 2, pp. 197-204, 2013.

[5] S. Legere, J. Harper, "Geotechnical Investigation for Enfield and Kelly Lake Scale House Pavement Upgrades," Exp HFX-00233545-A0, Halifax, NS, 28 July 2016.

[6] ASTM D6270 - 08 (Reapproved 2012) "Standard Practice for the Use of Scrap Tires in Civil Engineering Applications."

[7] Halifax C\&D Recycling Ltd, "Utilization and Construction of Type A TDA Engineered Subgrade Fill Underlying A Portland Cement Concrete Pavement (PCCP),” Halifax, NS, 17 July 2018. 